\title{
Selected Abbreviations
}

Nоте: Universally known abbreviations such as USSR and CIA are omitted from this list, as are the initials JFK and LBJ, used in note citations to refer to Presidents John F. Kennedy and Lyndon B. Johnson.

$\begin{array}{ll}\text { ARVN } & \text { Army of the Republic of Vietnam } \\ \text { CDEC } & \text { Combined Documents Exploitation Center } \\ \text { CINCPAC } & \text { Commander in Chief, Pacific } \\ \text { CPSU } & \text { Communist Party of the Soviet Union } \\ \text { DOD } & \text { Department of Defense } \\ \text { DRV } & \text { Democratic Republic of Vietnam } \\ \text { FBIS } & \text { Foreign Broadcast Information Service } \\ \text { FRUS } & \text { Foreign Relations of the United States } \\ \text { GVN } & \text { Government of Vietnam } \\ \text { ICC } & \text { International Control Commission } \\ \text { JCS } & \text { Joint Chiefs of Staff } \\ \text { JFKL } & \text { John Fitzgerald Kennedy Library, Boston } \\ \text { JPRS } & \text { Joint Publications Research Service } \\ \text { LBJL } & \text { Lyndon B. Johnson Library, Austin, Texas } \\ \text { MAAG } & \text { Military Assistance Advisory Group } \\ \text { MACV } & \text { Military Assistance Command Vietnam } \\ \text { NARA } & \text { National Archives and Records Administration } \\ \text { NIE } & \text { National Intelligence Estimate } \\ \text { NLF } & \text { National Liberation Front } \\ \text { NSC } & \text { National Security Council }\end{array}$




$\begin{array}{ll}\text { NSF } & \text { national security files, JFKL } \\ \text { OSD } & \text { Office of the Secretary of Defense } \\ \text { OSDH } & \text { Office of the Secretary of Defense, Historical Office } \\ \text { PKI } & \text { Partai Komunis Indonesia [Indonesian Communist Party] } \\ \text { PL } & \text { Pathet Lao } \\ \text { PLA } & \text { People's Liberation Army } \\ \text { PLAF } & \text { People's Liberation Armed Forces } \\ \text { PRC } & \text { People's Republic of China } \\ \text { RG } & \text { record group } \\ \text { RLG } & \text { Royal Lao Government } \\ \text { RVN } & \text { Republic of Vietnam } \\ \text { SEATO } & \text { Southeast Asia Treaty Organization } \\ \text { SMM } & \text { Saigon Military Mission } \\ \text { SNIE } & \text { Special National Intelligence Estimate } \\ \text { VNA } & \text { Vietnam National Army } \\ \text { VPA } & \text { Vietnam People's Army } \\ \text { VWP } & \text { Vietnam Workers' Party }\end{array}$

